Tropical Journal of Pharmaceutical Research October 2017; 16 (10): 2341-2347

ISSN: $1596-5996$ (print); 1596-9827 (electronic)

(C) Pharmacotherapy Group, Faculty of Pharmacy, University of Benin, Benin City, 300001 Nigeria.

All rights reserved.

Available online at http://www.tjpr.org

Original Research Article

http://dx.doi.org/10.4314/tjpr.v16i10.5

\title{
Development of extended-release formulation of domperidone using a blend of Raphia hookeri gum and hydroxypropyl methylcellulose as tablet matrix
}

\author{
Emmanuel O Olorunsola* and Stephen O Majekodunmi \\ Department of Pharmaceutics and Pharmaceutical Technology, University of Uyo, Uyo, Nigeria
}

*For correspondence: Email: olorunsolaeo@yahoo.com; Tel: +234-8035067306

Sent for review: 4 June 2017

Revised accepted: 23 September 2017

\begin{abstract}
Purpose: To develop an extended-release formulation of domperidone using a blend of Raphia hookeri gum and hydroxypropyl methylcellulose as tablet matrix.

Methods: Tablets (400 mg) containing $30 \mathrm{mg}$ domperidone (DPD) were formulated using binary mixtures of hydroxypropyl methylcellulose (HPMC) and Raphia hookeri gum (RHG) as matrix former; and microcrystalline cellulose (MCC) as direct compression excipient. The proportions of the matrix formers (40\% of tablet weight) was varied as 100:0, 75:25, 50:50, 25:75 and 0:100. The composition of the matrix former was also kept constant (50:50) while MCC was varied as 40, 30, 20 and $10 \%$. The tablets were evaluated for compact density, tensile strength, friability and drug release over $24 \mathrm{~h}$.

Results: The tensile strength of tablets decreased while their friability increased with increase in the proportion of RHG. A similar trend was observed with decrease in the concentration of MCC. Tablets containing RHG alone as matrix former and $40 \% \mathrm{MCC}$ as direct compression excipient had tensile strength of $0.95 \mathrm{MNm}-2$, friability of $1.07 \%$ and cumulative drug release of $83.2 \%$ over a period of $24 \mathrm{~h}$. Tablets containing equal proportions of HPMC and RHG as matrix former had the best release properties of $95.0 \%$ over a period of $24 \mathrm{~h}$.

Conclusion: RHG is comparable with HPMC in terms of extending the release of domperidone for a once daily administration. A suitable combination of the two polymers for use as a matrix former is superior to either of the individual polymers.
\end{abstract}

Keywords: Domperidone, Extended drug release, Hydroxypropyl methylcellulose, Raphia hookeri gum, Tablet properties

Tropical Journal of Pharmaceutical Research is indexed by Science Citation Index (SciSearch), Scopus, International Pharmaceutical Abstract, Chemical Abstracts, Embase, Index Copernicus, EBSCO, African Index Medicus, JournalSeek, Journal Citation Reports/Science Edition, Directory of Open Access Journals (DOAJ), African Journal Online, Bioline International, Open-J-Gate and Pharmacy Abstracts

\section{INTRODUCTION}

Tablets are the most popular pharmaceutical dosage forms having numerous advantages. These advantages include: ease and low cost of production, high stability, possibility of masking objectionable odour and bitter taste, ease of product identification, portability, precise dosing and ease of administration [1]. Another major advantage of tableting is the possibility of formulation as controlled release systems [2].
Such systems are useful for modifying duration of action, reducing frequency of administration and increasing therapeutic effect; and thus increasing patients' compliance and optimizing therapeutic outcome [3]. The major challenge is the need for appropriate excipients for such delivery systems [4].

Raphia hookeri (Family: Palmae) is the largest palm in Africa and is widely distributed in lowland swamps of western and central sub-regions of 
the continent [5]. The work of Olorunsola et al. [6] showed that the exudates of the plant contain 28 $\%{ }^{w} / w$ gum and that $3 \%{ }^{W} / w$ dispersion of the gum has $\mathrm{pH}$ of 4.09 and viscosity of 208.60 $\mathrm{mPa}$.s (measured using spindle 2 at $60 \mathrm{rpm}$ and $\left.27.4{ }^{\circ} \mathrm{C}\right)$. Raphia hookeri gum has been evaluated for binding properties in conventional tablets at concentration of $1-5 \%{ }^{w / w}$ in comparison with gelatin using wet granulation method [7]. It was observed that granules of formulations containing gelatin had better flow properties. It was also observed that tablets containing RHG were characterized by better mechanical properties, longer disintegration time and slower dissolution rate. This is a pointer to the suitability of the polymer for an extended delivery. However, exploitation of this polymer for such purpose was not obtainable from available literature.

Domperidone is a specific blocker of dopamine receptor. It is a prokinetic that speeds up gastrointestinal movement [8]. It is used for the management of dyspepsia, epigastric pain and heart burn. It is also used as an antiemetic [8]. It is a weakly basic drug with good solubility in acidic medium [9]. The elimination half-life is 5 $7 \mathrm{~h}$, the oral bioavailability is $13-17 \%$ and the adult dose is $10 \mathrm{mg}$ three times daily [9]. These pharmacokinetic parameters prompted the development of an extended release formulation of the drug using suitable polymers to reduce the frequency of administration of the drug. This study was aimed at formulating an extended release system of the drug (using a blend of Raphia hookeri gum and hydroxypropyl methylcellulose) for once daily administration.

\section{EXPERIMENTAL}

\section{Materials}

Domperidone was obtained as a gift from May and Baker PLC Lagos, Nigeria. Hydroxypropyl methylcellulose (Spectracel 15E, low molecular weight) was a gift from Sensient, St. Louis, USA. Microcrystalline cellulose was purchased from
E.merk, Darmstadt; while lactose was purchased from Riedel De Haenac seelze, Hannover. Raphia hookeri gum was obtained from the previous work of Majekodunmi and Makper [7]. All other materials used were of analytical grade.

\section{Compatibility studies}

A sample each of domperidone, Raphia hookeri gum and a physical mixture of the two materials was prepared in a $\mathrm{KBr}$ disk. The FTIR spectra were recorded over a scanning range of 350 to $4000 \mathrm{~cm}^{-1}$ using a spectrophotometer (Shimadzu Corporation, model 8400S, Kyoto-Japan).

\section{Preparation of extended-release tablets of domperidone}

Domperidone tablets were formulated based on the formula in Table 1. All the ingredients as specified for each formulation (F1 to F8) were weighed and then mixed thoroughly. Flat $400 \mathrm{mg}$ tablets were produced by direct compression using $\mathrm{F}_{3}$ single station tableting machine (Cadmach Machinery Co. PVT., India) fitted with $12.50 \mathrm{~mm}$ punches.

\section{Evaluation of tablet formulations}

\section{Weight and dimensions}

Five (5) tablets from each batch were weighed individually using an analytical balance (Mettler, Germany). The dimensions (diameter and thickness) of the tablets were also determined using digital vernier caliper.

\section{Crushing strength}

The crushing strength of the five selected tablets per batch was determined using Monsanto hardness tester [10]. The crushing strength was taken as the force required to break a tablet when the pressure generated by the coiled spring of the hardness tester was applied diametrically.

Table 1: Tablet composition

\begin{tabular}{lcccccccc}
\hline Ingredient (mg/tablet) & F1 & F2 & F3 & F4 & F5 & F6 & F7 & F8 \\
\hline Domperidone & 30 & 30 & 30 & 30 & 30 & 30 & 30 & 30 \\
Hydroxypropyl methylcellulose & 160 & 120 & 80 & 40 & 0 & 80 & 80 & 80 \\
Raphia hookeri gum & 0 & 40 & 80 & 120 & 160 & 80 & 80 & 80 \\
Lactose & 50 & 50 & 50 & 50 & 50 & 90 & 130 & 170 \\
Microcrystalline cellulose & 160 & 160 & 160 & 160 & 160 & 120 & 80 & 40 \\
\hline Total & $\mathbf{4 0 0}$ & $\mathbf{4 0 0}$ & $\mathbf{4 0 0}$ & $\mathbf{4 0 0}$ & $\mathbf{4 0 0}$ & $\mathbf{4 0 0}$ & $\mathbf{4 0 0}$ & $\mathbf{4 0 0}$ \\
\hline
\end{tabular}




\section{Compact density}

Tablet density (D) was calculated using the mass, diameter and thickness of the five tablets selected randomly from each batch and by applying Eq 1 [11].

$D=m / \pi r^{2} h$

where $m$ is the mass of tablet, $r$ the radius and $h$ thickness.

\section{Tensile strength}

Tensile strength $(T)$ was calculated using the crushing strength, diameter and thickness of the five tablets from each batch and by applying Eq 2 [12].

$\mathrm{T}=2 \mathrm{~F} / \pi \mathrm{dt}$

where $F$ is the crushing strength, $d$ the diameter and $t$ thickness of tablets.

\section{Friability}

Ten tablets were dedusted, weighed together and then subjected to abrasion test in a frabilator (Erweka, Germany) operated at $25 \mathrm{rpm}$ for $4 \mathrm{~min}$. The tablets were dedusted again and then reweighed together [10]. The difference in weight was determined and the friability value was calculated as the ratio of difference in weight to the initial weight expressed as a percentage.

\section{Dissolution}

In-vitro dissolution test for the tablets was carried out using the basket method in USP dissolution test apparatus. The tablet was placed in a wire mesh basket suspended in a dissolution medium of $900 \mathrm{ml} 0.1 \mathrm{~N} \mathrm{HCl}$ maintained at temperature of $37 \pm 1{ }^{\circ} \mathrm{C}$. The basket was rotated at a speed of $50 \mathrm{rpm}$ and the experiment was allowed for $24 \mathrm{~h}$. Aliquots $(10 \mathrm{ml})$ was withdrawn at 1.5, 3, 6, 9, 12, 18 and $24 \mathrm{~h}$. Each sample was filtered through Whatman Grade No. 4 filter paper and the absorbance was taken at $287 \mathrm{~nm}$ using UV spectrophotometer (Jenway, England). The cumulative percent drug released was calculated using Eq 3. A graph of cumulative percent drug released was plotted against time [10].

$\mathrm{R}(\%)=\frac{A D}{S D} \times 100 \%$

where $R$ is cumulative percent drug released, $A$ is the absorbance of solution of drug released at the specified time, $V$ is the volume of dissolution medium, $\mathrm{S}$ is the slope of the calibration curve of absorbance and $D$ is the amount of drug per tablet.

\section{Statistical analysis}

Data are expressed as mean \pm standard deviation (SD). The analysis was carried out using one-way analysis of variance followed by multiple comparison tests with the aid of GraphPad Instat-3 tool. Significance of difference was set at $p<0.05$.

\section{RESULTS}

\section{Fourier transform infrared (FTIR) spectra}

The FTIR spectra of domperidone, Raphia hookeri gum and that of their physical mixture are shown in Figure 1. The spectrum of domperidone showed twenty-two identifiable peaks, that of Raphia hookeri gum showed nine identifiable peaks while that of the physical mixture showed fifteen identifiable peaks.

\section{Effect of polymer ratio on physical properties of tablets}

The effect of polymer ratio of matrix former (HPMC : RHG) on compact density, tensile strength and friability of tablets is shown in Table 2. There was a significant difference in the compact density of $\mathrm{F} 1$ and those of other formulations (F2, F3, F4 and F5). There were no significant differences in the compact densities of F2, F3, F4 and F5. The tensile strength decreased with increase in the proportion of RHG in the matrix former and the values were significantly different $(p<0.05)$. Formulations $\mathrm{F} 1$, F2 and F3 had friability values less than $1 \%$ while F4 and F5 had values greater than $1 \%$.

\section{Effect of polymer ratio on drug release}

The plots of cumulative percent drug released versus time for F1, F2, F3, F4 and F5 are shown in Figure 2. The cumulative percent drug released at every time increased from $\mathrm{F} 1$ down to $F 4$ (that is, with increase in the proportion of RHG in the matrix former). The trend changed in the case of $\mathrm{F} 5$; the cumulative percent drug release at $24 \mathrm{~h}(83.2 \%)$ being lower than for F3 and F4. Formulation F4 brought forth complete drug release within $12 \mathrm{~h}$.

\section{Effect of MCC concentration on physical properties of tablets}

The effect of concentration of microcrystalline cellulose on compact density, tensile strength and friability of tablet is shown in Table 3 . There 
were no significant differences in the compact density of the four formulations. Also, there were no significant differences in the tensile strength of F6, F7 and F8 but formulation F3 has a significantly higher tensile strength. The values of tensile strength decreased with decrease in the concentration of MCC. The friability of tablet also increased with decrease in the concentration of MCC and only F3 had friability value less than 1 $\%$.

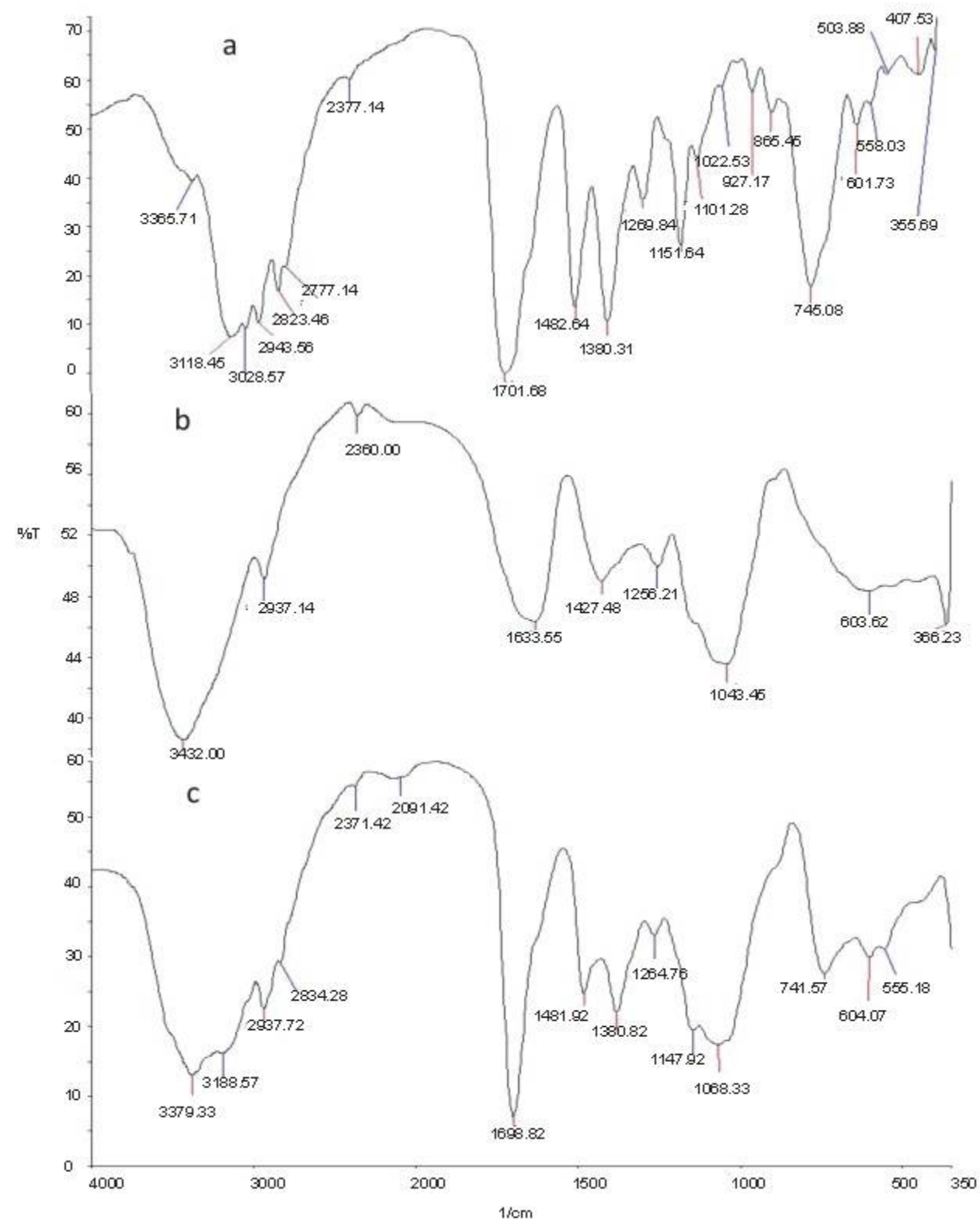

Figure 1: FTIR spectra of (a) domperidone (b) Raphia hookeri gum (c) physical mixture of domperidone and Raphia hookeri gum

Table 2: Effect of polymer ratio on tablet properties

\begin{tabular}{lcccc}
\hline Batch & $\begin{array}{c}\text { Ratio of matrix formers } \\
\text { HPMC:RHG }\end{array}$ & $\begin{array}{c}\text { Compact density } \\
\left(\mathbf{g} / \mathbf{c m}^{3}\right)\end{array}$ & $\begin{array}{c}\text { Tensile strength } \\
\left(\mathbf{M N} / \mathbf{m}^{2}\right)\end{array}$ & $\begin{array}{c}\text { Friability } \\
(\%)\end{array}$ \\
\hline F1 & $100: 0$ & $1.39 \pm 0.03$ & $1.76 \pm 0.38$ & $0.63 \pm 0.05$ \\
F2 & $75: 25$ & $1.29 \pm 0.01$ & $1.53 \pm 0.19$ & $0.67 \pm 0.00$ \\
F3 & $50: 50$ & $1.29 \pm 0.01$ & $1.21 \pm 0.32$ & $0.90 \pm 0.02$ \\
F4 & $25: 75$ & $1.29 \pm 0.01$ & $1.03 \pm 0.14$ & $1.04 \pm 0.00$ \\
F5 & $0: 100$ & $1.28 \pm 0.00$ & $0.95 \pm 0.13$ & $1.07 \pm 0.00$ \\
\hline
\end{tabular}




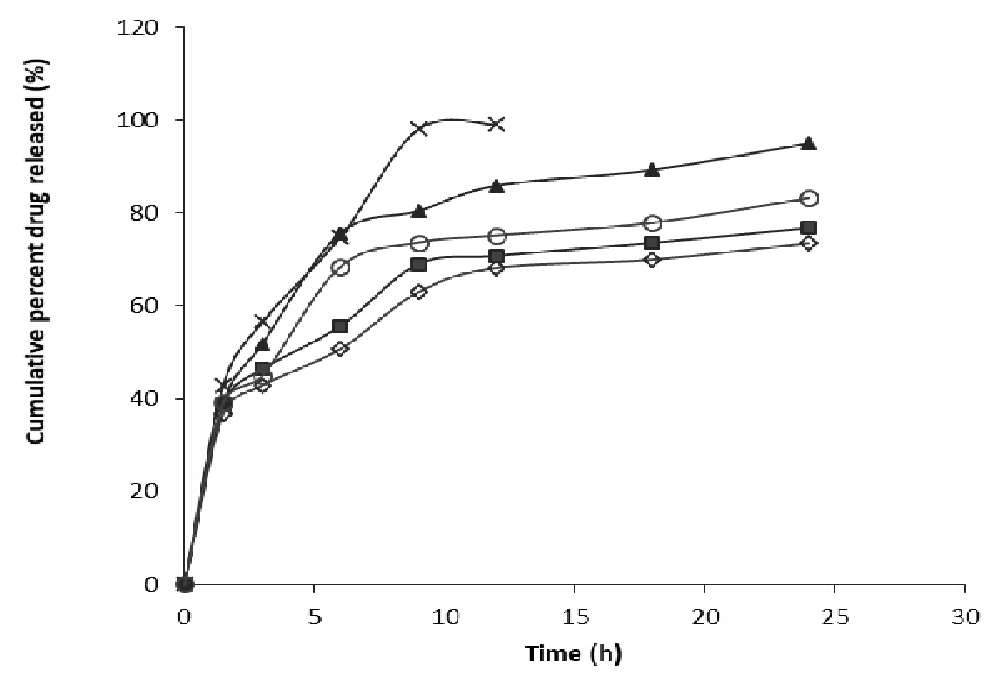

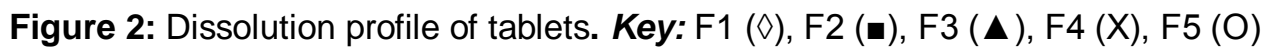

Table 3: Effect of concentration of MCC on physical properties of tablets

\begin{tabular}{lcccc}
\hline Batch & $\begin{array}{c}\text { Concentration of MCC } \\
(\%)\end{array}$ & $\begin{array}{c}\text { Compact density } \\
\left(\mathbf{g} / \mathbf{c m}^{\mathbf{3}}\right)\end{array}$ & $\begin{array}{c}\text { Tensile strength } \\
\left(\mathbf{M N} / \mathbf{m}^{2}\right)\end{array}$ & $\begin{array}{c}\text { Friability } \\
(\%)\end{array}$ \\
\hline F3 & 40 & $1.29 \pm 0.01$ & $1.21 \pm 0.32$ & $0.90 \pm 0.02$ \\
F6 & 30 & $1.29 \pm 0.01$ & $0.93 \pm 0.16$ & $1.32 \pm 0.11$ \\
F7 & 20 & $1.28 \pm 0.01$ & $0.89 \pm 0.03$ & $1.36 \pm 0.15$ \\
F8 & 10 & $1.28 \pm 0.02$ & $0.68 \pm 0.11$ & $1.55 \pm 0.03$ \\
\hline
\end{tabular}

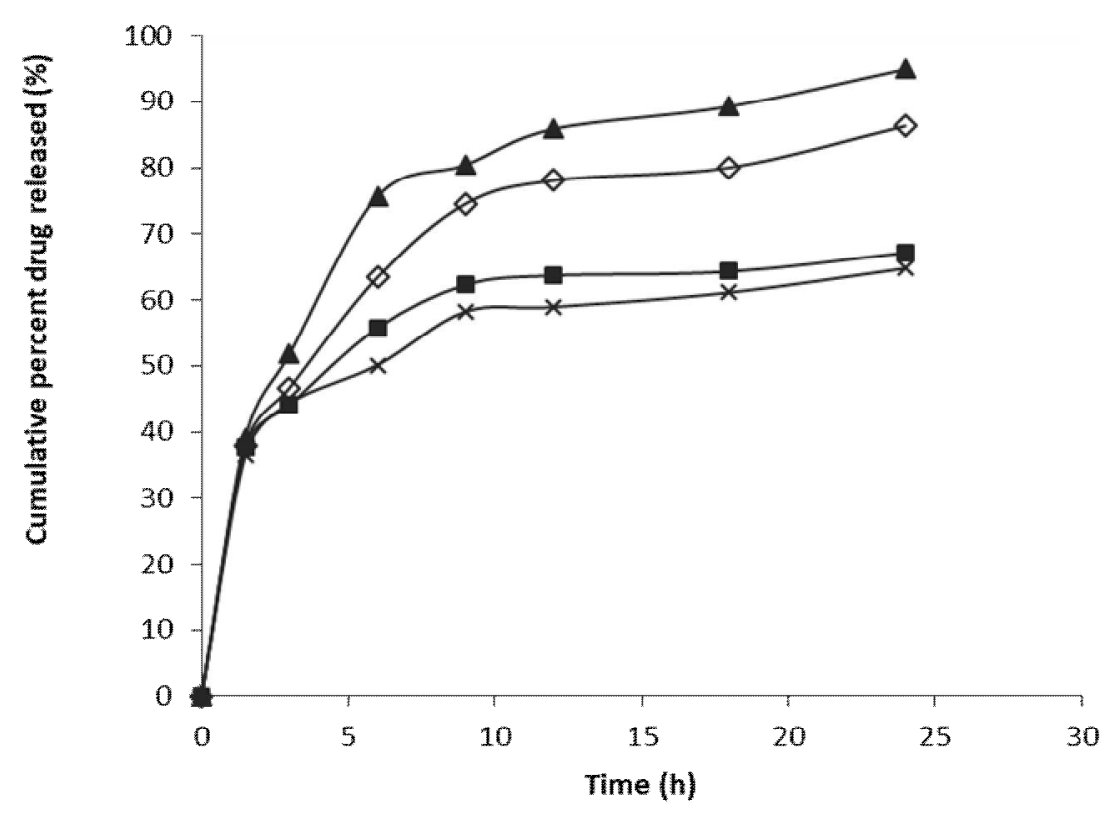

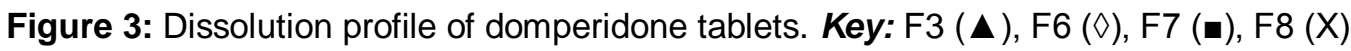

\section{Effect of MCC concentration on drug release}

The plots of cumulative percent drug released versus time for formulations F3, F6, F7 and F8 are shown in Figure 3 . The rate of drug release and the total drug release at $24 \mathrm{~h}$ followed the same trend of F3 $>$ F6 $>$ F7 $>$ F8.

\section{DISCUSSION}

The decrease in the number of peaks in the spectrum of the physical mixture can be ascribed to superimposition of peaks and not formation of a new compound. Also, the retention of all the major peaks of domperidone in the spectrum of the physical mixture shows that there was no

Trop J Pharm Res, October 2017; 16(10): 2345 
adverse interaction between the drug and the gum. Therefore, Raphia hookeri gum is compatible with the drug [13].

The characteristics of formulations F1, F2, F3, F4 and F5 illustrate the effect of the composition of the matrix former on domperidone tablets. Tablet formulation containing hydroxypropyl methylcellulose alone as a matrix former (F1) was characterized by the highest compact density. The tablets from this formulation are relatively smaller in size since density is inversely related to volume. The other formulations (F2, F3, F4 and F5) are not significantly different in size since there was no significant difference in their density. Hence, using a blend of RHG and HPMC as tablet matrix for domperidone will produce tablet of bigger size compared to using HPMC alone.

The presence of RHG caused a decrease in tensile strength of tablets. Tensile strength is a measure of strength of tablets and it is influenced by the degree of plastic deformation experienced by a polymer [14]. Hence, the degree of plastic deformation experienced by RHG could be less than that of HPMC. Tensile strength as a parameter of tablet strength is absolute as it takes into consideration the thickness and diameter of the tablet.

Friability of less than $1 \%$ is required for a tablet to pass friability test $[10,15]$. Formulations $F 1$, F2 and F3 passed the test for friability while formulations F4 and F5 failed. Friability is a measure of tablet weakness and it shows the susceptibility of tablet to abrasion as it moves from the point of production down to point of administration. The friability values show that the tablet weakness increases with increase in the proportion of RHG in the matrix former.

Out of the five formulations, F1 brought forth the lowest drug release at $24 \mathrm{~h}$. Hence, the formulation is the most effective in sustaining the drug release. However, it gave incomplete drug release as at the $24 \mathrm{~h}$. The cumulative percent drug release increased with increase in the proportion of RHG in the matrix former. Formulation F4 brought forth almost complete drug release within $12 \mathrm{~h}$ and cannot sustain the release for a $24 \mathrm{~h}$ period. Formulation F3 (containing HPMC and RHG in ratio $1: 1$ as matrix former) gave about complete drug release at $24 \mathrm{~h}$. The work of Sakurai et al. [16] showed that combination of HPMC with co-polyvidone or polyvinylpyrrolidone led to increase stability and solubility owing to solid dispersion effect on each other. Thus, the increased drug release when HPMC and RHG were combined could be attributed to solid dispersion effect on each other. The suitability of combination of these two polymers can be linked to two factors namely: ability of both polymers to sustain drug release and the solid dispersion effect of the two polymers to improve extent of drug release.

Raphia hookeri gum alone as a matrix former (F5) brought forth cumulative percent drug release which is comparable with that of HPMC. Hence, the polymer is comparable with HPMC in sustaining the release of domperidone over a 24 $\mathrm{h}$ period. It is suitable for a once daily formulation with total drug release of $83.2 \%$.

The characteristics of formulations F3, F6, F7 and F8 reflect the effect of concentration of MCC on domperidone tablets. The concentration of MCC had no significant effect on the compact density. Therefore, the concentration of the direct compression excipient has no significant effect on the tablet size since there is an inverse relationship between volume and density as earlier stated.

The tensile strength decreased as the concentration of the direct compression excipient was decreased. This observation was not unexpected because the MCC was incorporated to provide the binding effect. It can be inferred that even though the concentration of the direct compression excipient has no significant effect on the compactness of tablet, it has a significant effect on its coherence.

As earlier stated, a friability of less than $1 \%$ is expected for a tablet to pass friability test [10, 15]. Only F3 (which contains $40 \%$ MCC) passed the test. Since both tablet strength (tensile strength) and weakness (friability) must be assessed to ensure acceptable mechanical properties of tablet, MCC at the concentration of $40 \%$ produced tablet with the best mechanical property.

The four formulations (F3, F6, F7 and F8) were able to sustain release of domperidone over a period of $24 \mathrm{~h}$. However, the extent of drug release decreased with decrease in the concentration of MCC. The high extent of drug delivery at high concentration of MCC can be attributed to the disintegration effect of the polymer [17]. It can also be attributed to better solid dispersion effect of the three polymers (HPMC, RHG and MCC) on one another [16].

\section{CONCLUSION}

Raphia hookeri gum is comparable to HPMC as a matrix former in sustaining drug release over a 
period of $24 \mathrm{~h}$ although it is characterized by reduced tablet strength. A combination of the two polymers as a matrix former is suitable for enhancing the extent of drug release. Hence, this combination can be further developed as a matrix former for once-daily administration of domperidone.

\section{DECLARATIONS}

\section{Acknowledgement}

The authors are grateful to May and Baker Plc Lagos, Nigeria for the gift of domperidone powder, and to Sensient, St Louis, USA for the gift of hydroxypropyl methylcellulose.

\section{Conflict of Interest}

No conflict of interest associated with this work.

\section{Contribution of Authors}

The authors declare that this work was done by the authors named in this article and all liabilities pertaining to claims relating to the content of this article will be borne by them.

\section{Open Access}

This is an Open Access article that uses a funding model which does not charge readers or their institutions for access and distributed under the terms of the Creative Commons Attribution License (http://creativecommons.org/licenses/by/ 4.0) and the Budapest Open Access Initiative (http://www.budapestopenaccessinitiative.org/rea d), which permit unrestricted use, distribution, and reproduction in any medium, provided the original work is properly credited.

\section{REFERENCES}

1. Tiwari AK., Shah $H$, Raypoot A, Singhal M. Formulation and in-vitro evaluation of immediate release tablets of drotaverine HCl. J Chem Pharm Res 2011; 3(4): 333341.

2. Sun $X F$, Wang $H H$, Jing $Z X$, Mohanathas $R$. Hemicellulose-based $\mathrm{pH}$-sensitive and biodegradable hydrogel for controlled drug delivery. Carbohydrate Polym 2013; 92(2): 1357-1366.

3. Gudigennavar AS, Vijapur LS, Patil CC, Kulkarni RV. Development and evaluation of gastro-retentive drug delivery systems of cefuroxime axetil. Afr $J$ Pharm Pharmacol 2013; 7(20): 332-338.
4. Chavanpatil $M$, Jain $P$, Chaudhari $S$, Shear $R$, Vavia $P$. Development of sustained release gastroretentive drug delivery system for ofloxacin: In vitro and in vivo evaluation. Int J Pharm 2005; 304: 178-184.

5. Ndon BA. The Raffia Palm, 1st Ed. Nigeria: Concept Publications Ltd., 2003.

6. Olorunsola EO, Adedokun MO, Okon AA. Determination of hydrophile - lipophile balance value of Raphia hookeri Mann (Palmae) gum by emulsification method. Nig $J$ Pharm Res 2016; 12(1): 31-35.

7. Majekodunmi SO, Makper S. Development and evaluation of the binding properties of Raphia hookeri (Fam. Palmaceae) gum in pharmaceutical tablet formulation. Brit J Pharm Res 2016; 14(3): 1-9.

8. McQuaid KR. Drugs used in the treatment of gastrointestinal diseases. In: Katzung, Bertram G., editor. Basic and Clinical Pharmacology. 9th ed. Singapore: The McGraw-Hill Companies Inc. 2004. p. 1034-1061.

9. Helmy SA, El Bedaiwy HM. Pharmacokinetics and comparative bioavailability of domperidone suspension and tablet formulations in healthy adult subjects. Clin Pharmacol Drug Dev 2014; 3(2): 126-131.

10. Olorunsola EO, Uwah TO, Olayemi OJ, Etukudo UB, EX vivo evaluation of crab shell chitosan as absorption enhancer in ciprofloxacin tablet. Afr J Biotechnol 2016; 15(36): 1930-1935.

11. Odeku OA, Awe OO, Popoola B, Odeniyi MA, Itiola OA, Compression and mechanical properties of tablet formulations containing corn, sweet potato and cocoyam starches as binders. Pharm Technol 2005; 29: 82-90.

12. Halenius A, Lakio S, Antikainen $O$, Hatara J, Yliruus J. Fast tablet tensile strength prediction based on noninvasive analytics. AAPS PharmSciTech 2014; 15(3): 781- 791.

13. Nutan MTH, Suliman MS, Taha El, Khan MA. Optimization and characterization of controlled release multi-particulate beads with starch acetate. Int $J$ Pharm 2005; 294: 89-101.

14. Odeku OA, Itiola OA. Compaction properties of three types of Starch. Iran J Pharm Res 2007; 6(1): 17-23.

15. Alderborn G. Tablets and compaction. In: Aulton, Michael E., editor. The Design and Manufacture of Medicine. 3rd ed. Hungary: Churchill Livingstone Elsevier. 2007. $p$. 461-482

16. Sakurai A, Sakai T, Sako K, Maitani Y. Polymer combinations increase both physical stability and oral absorption of solid dispersion containing a low glass transition temperature drug: physicochemical characterization and in-vivo study. Chem Pharm Bull 2012; 60(4): 459-464.

17. Rojas J, Kumar V. Evaluation of the disintegration properties of microcrystalline cellulose II and commercial disintegrants. Pharmacie 2012; 67(6): 500506. 